Article

\title{
Microscopic Imaging Technology Assisted Dynamic Monitoring and Restoration of Micron-Level Cracks in the Painted Layer of Terracotta Warriors and Horses of the Western Han Dynasty
}

\author{
Juanli Wang ${ }^{1}$, Jiaxin Li $^{1}$, Xiaolian Chao ${ }^{1}$, Youlu Chen ${ }^{2}$, Yongsheng Huang ${ }^{2}$, Bingjie Mai ${ }^{1, *(D), ~ Y u h u ~ L i ~}{ }^{1, *}$ \\ and Jing Cao ${ }^{1, *(D)}$
}

1 Engineering Research Center of Historical and Cultural Heritage Protection, Ministry of Education, School of Materials Science and Engineering, Shaanxi Normal University, Xi'an 710119, China; wangjuanli@snnu.edu.cn (J.W.); tuoyuanxinggungun@snnu.edu.cn (J.L.); chaoxl@snnu.edu.cn (X.C.)

2 Cultural Relics Restoration Department, Xianyang Museum, Xianyang 712000, China; skycyl666@163.com (Y.C.); huangyongsheng69@163.com (Y.H.)

* Correspondence: maibingjie@snnu.edu.cn (B.M.); liyuhu@snnu.edu.cn (Y.L.); jingcao@snnu.edu.cn (J.C.)

Citation: Wang, J.; Li, J.; Chao, X.; Chen, Y.; Huang, Y.; Mai, B.; Li, Y.; Cao, J. Microscopic Imaging Technology Assisted Dynamic Monitoring and Restoration of Micron-Level Cracks in the Painted Layer of Terracotta Warriors and Horses of the Western Han Dynasty. Polymers 2022, 14, 760. https:// doi.org/10.3390/polym14040760

Academic Editor:

Mariaenrica Frigione

Received: 8 January 2022

Accepted: 13 February 2022

Published: 15 February 2022

Publisher's Note: MDPI stays neutral with regard to jurisdictional claims in published maps and institutional affiliations.

Copyright: (c) 2022 by the authors Licensee MDPI, Basel, Switzerland. This article is an open access article distributed under the terms and conditions of the Creative Commons Attribution (CC BY) license (https:// creativecommons.org/licenses/by/ $4.0 /)$

\begin{abstract}
Cracks are one of the most common issues affecting colored pottery relics; these can be divided into macroscopic cracks, recognizable by the human eye, and micron cracks, which cannot be observed by the naked eye. The gradual development of micron cracks eventually leads to large-scale cracks and the shedding of the coating layer. The repair of such micron cracks poses a key technical difficulty in restoring painted pottery remnants from the Western Han Dynasty. We attempt to solve this problem by reporting on a method that entails the use of a water-borne fluoropolymer material as the adhesive agent, as well as ultra-depth-of-field, digital microscopic imaging technology to build an operating platform for an optical imaging monitoring system. By making simulated ceramic samples, we systematically investigated the influences of water-borne fluoropolymer on chromaticity, adhesion, contact angle, surface morphology, and thermal stability of the paint layer. The results indicate that the color of the painted layer, when treated with the water-borne fluoropolymer, did not change, and the adhesion and contact angle of the painted layer were improved. Additionally, the outcomes of the SEM analysis show that the adhesion and hydrophobicity of the painted layer were improved because the water-borne fluoropolymer filled up the porous structure of the painted layer and covered the pigment particles. These findings demonstrate that aqueous, water-borne fluoropolymer can be used as an adhesive agent for micron cracks. Meanwhile, via the operating platform of the optical imaging monitoring system, the micron cracks of the painted terracotta warriors and horses from the Western Han Dynasty were successfully repaired using the water-borne fluoropolymer. The results imply that the microstructure, size, and geometric spaces of the cracks can be obtained directly utilizing microscopic imaging technology. The dynamic monitoring and imaging system described above can be employed to assist prosthetists in visualizing micro-repair operations in real time, assist with fine visual operations during the repair process, and realize dynamic video recording of the entire repair process. Our work provides a simple visualization method to repair micron-scale cracks in painted pottery relics by applying modern fluoropolymer and ultra-depth-of-field digital microscopic imaging technology.
\end{abstract}

Keywords: terracotta warriors and horses; micron cracks of the painted layer; microscopic imaging technology; dynamic monitoring; restoration

\section{Introduction}

The painted terracotta warriors unearthed from the Western Han Dynasty are mainly concentrated in three places: Yangjiawan [1,2], the Hanyang Mausoleum [3,4] in Shaanxi, and at the western foot of Lion Mountain in Yunlong District in the city of Xuzhou [5]. They provide important information for research on the society, culture, art, and customs of the 
Western Han Dynasty, including the tomb system, the combination of infantry equipment, the organizational equipment of the cavalry, the military system, battle formations, arms, costume craftsmanship, and pottery craftsmanship. Half a century after their excavation, the painted terracotta warriors and horses of the Western Han Dynasty in Yangjiawan, Shaanxi are now displayed at the Xianyang Museum [6] in the city of Xianyang, Shaanxi Province (the location of the painted terracotta warriors and horses of the Western Han Dynasty in Yangjiawan, Shaanxi is shown in Figure 1).

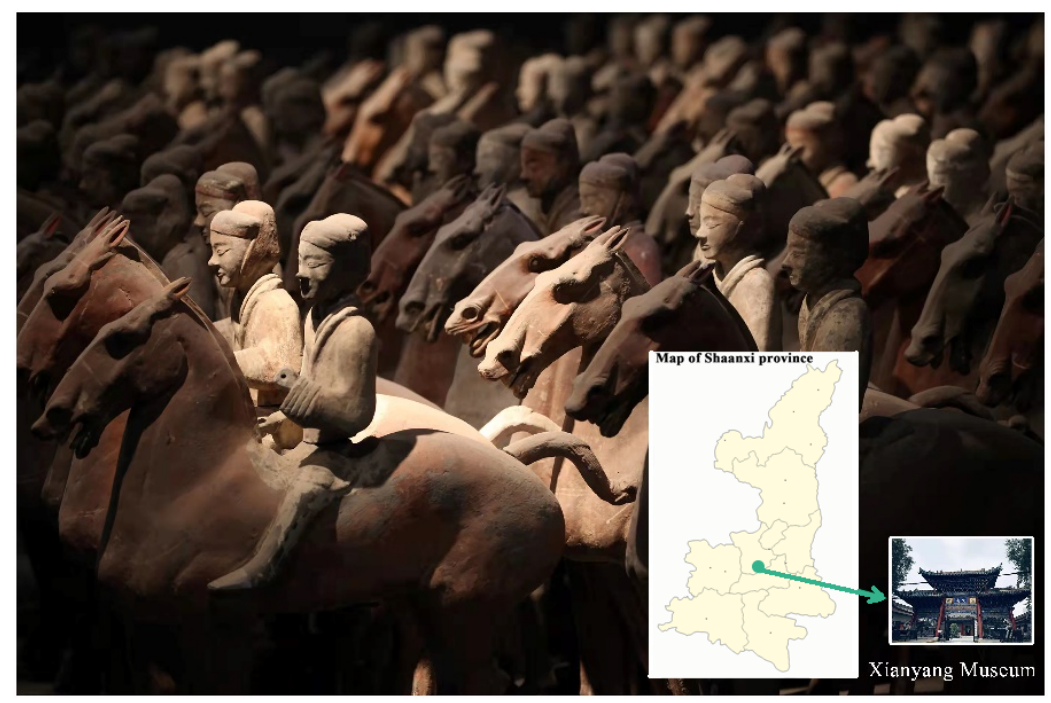

Figure 1. Location of the painted terracotta warriors and horses of the Western Han Dynasty in Yangjiawan, Shaanxi.

The cracks and shedding that occur after painted pottery figurines and pottery horses are unearthed are the most common problems of painted cultural relics (see Figure 2). There are many reasons for their appearance, and some result from a combination of multiple factors [7]. Because these cultural pottery relics were in a highly humid and hypoxic environment for thousands of years before they were unearthed, their environment changed drastically after they were uncovered. When humidity is high, the pigment particles and binder of the painted layer will absorb water and expand; by contrast, when humidity is reduced, the pigment particles and binder of the painted layer will lose water and shrink. Because the shrinkage force of the pigment particles is smaller than that of the binder, the adhesion on the surface of the painted pottery figurines in the pigment layer is reduced, eventually leading to peeling. However, given the material of such pottery, a considerable portion of the cracked and warped painted layer is due to a layer of pottery clothing being made of inorganic materials on the pottery body. Alternatively, because the surface of the pottery body is dense and smooth, the painted layer does not permeate into the pottery body; thus, the adhesion between the painted layer and the pottery clothing or the surface of the smooth and compact pottery body is weakened, resulting in separation. Additionally, due to the aging of the paint layer sizing material, the adhesion of the pigment layer on the pottery clothing surface is reduced, resulting in shedding.

In view of such cracks, the adhesive agent is directly injected into the crack's inner area, which is meant to improve the adhesion of pigment particles and the pottery matrix. In the past, due to its compatibility with the original cementing material, natural glue (e.g., animal gelatine and peach gum) was used as a reinforcement and binder for the protective treatment of paintings [8]. However, in the second half of the 20th century, research on synthetic polymers opened up new possibilities for restorers due to their decreased sensitivity to relative humidity and visible or ultraviolet light [9]. Currently, polyvinyl alcohol, polyethylene butyrate, ethyl cellulose, polyvinyl acetate, acrylic resins (such as ethyl methacrylate/methyl acrylate copolymer [Paranoid B72]), water-based polyurethane, 
and fluorocarbon resin are used as synthetic polymers [10-17]. In recent years, FEVE fluoropolymers have become widely used given their excellent weather resistance [18,19].

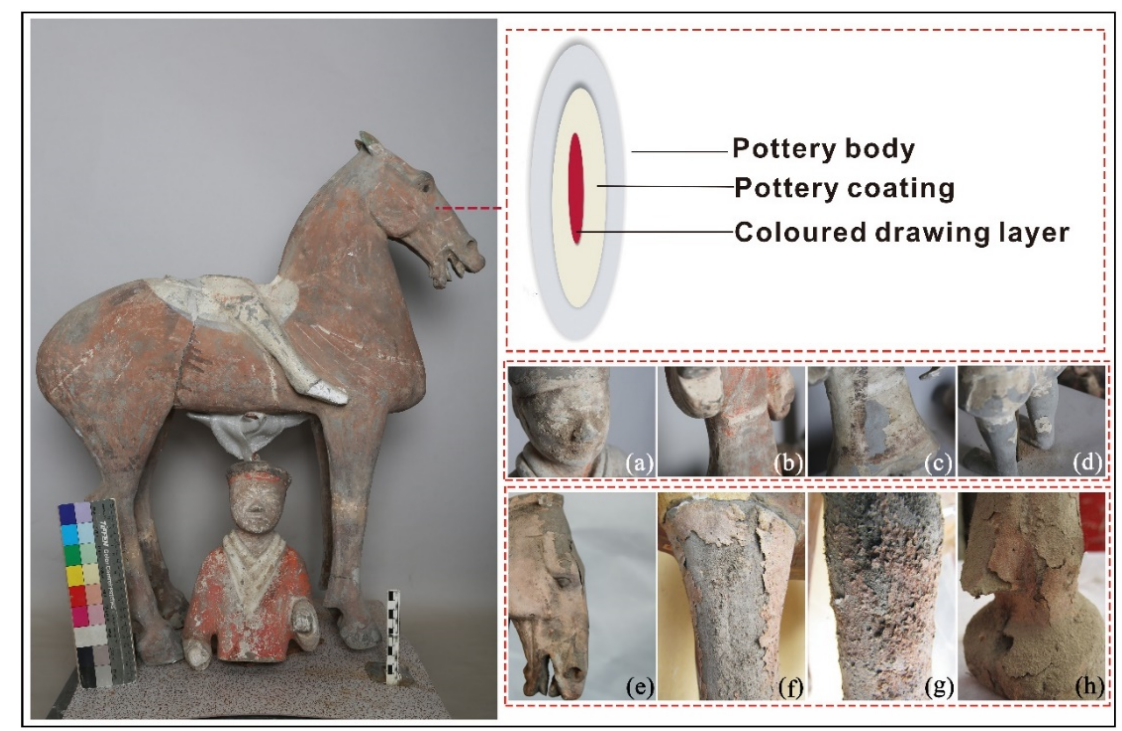

Figure 2. Structure and typical conditions of the painted layer of terracotta warriors and horses from the Western Han Dynasty; (a) crisp powder, (b) warping, (c) cracking, (d) shedding, (e) warping, (f) shedding, (g) crisp powder, (h) cracking.

For the painted terracotta warriors and horses of the Western Han Dynasty, cracks in the painted layer are relatively common. The cracks in the painted terracotta warriors and horses of the Western Han Dynasty can be primarily divided into two types: The first kind is visually identifiable. Generally, a crack bigger than $0.1 \mathrm{~mm}$ can be recognized by the human eye. This includes the severity of the painted layer falling off and the exposed pottery body; if the painted layer is cracked, warped, and hollow, it may be in danger of falling off. The second type of crack is at the micron level; it is less than $0.1 \mathrm{~mm}$ in size and cannot be seen with the human eye. The gradual development of these micron-level cracks eventually leads to large-scale cracks and the shedding of the painted layer. Herein, we discuss the restoration of such micron-level cracks, about which there have been few reports.

Modern optical inspection technology has developed rapidly, and optical inspection equipment has been widely used in the evaluation, protection, and restoration of artwork $[20,21]$. An imaging system can be constructed by using imaging principles and a special light source to efficiently assess a piece of art.

By harnessing ultra-depth-of-field digital microscopy imaging technology $[22,23]$ to build an optical imaging monitoring system operating platform, along with the commercial water-borne FEVE (ZB-F600) as adhesive agent, the micron-level cracks of the terracotta warriors of the Western Han Dynasty were repaired. ZB-F600 water-borne fluoropolymer is a copolymer of trifluoro vinyl chloride, vinyl acetate, allyl alcohol, and fatty acids. It has excellent weather resistance, durability, solubility, transparency, wettability, and adhesion; these characteristics justify the use of ZB-F600 as an adhesive agent in repairing micronlevel cracks. To verify this hypothesis, the color difference, adhesion, contact angle, and surface morphology of the painted layer were tested before and after treatment. Meanwhile, in the repair process, the system's digital microscopic imaging was able to directly obtain information on the microscopic morphology, size, and geometric spaces of the cracks. Thus, a dynamic monitoring and imaging system can be used to assist prosthetists with: realtime visualization of micro-restoration operations, the visual imaging and identification of micron-level cracks, and the video recording of the entire restoration process. 


\section{Status of Preservation}

Due to the different environments of the artwork displayed in the museum before being unearthed, the state of preservation of the excavated terracotta warriors and horses is a matter of concern. In addition to weathering, fading, limb breakage, and brokenness, a considerable portion of the painted layer has experienced warping [24,25], shedding [26,27], and cracking, and exhibits a crisp powder. With time, the condition of such artwork has become more serious, and a substantial part of precious information is on the verge of disappearing [28].

\section{Equipment and Methods}

\subsection{Preparation of Simulated Painted Pottery}

(i) The ceramic pieces were made from the soil collected from Yangjiawan (Xianyang, Shaanxi, China), the excavation area of the painted terracotta warriors and horses of the Western Han Dynasty. A plaster mold was used to shape them into cubes of $12 \times 12 \times 0.5 \mathrm{~cm}^{3}$ by hand and fired at 900 degrees Celsius. The samples were cut into cubes of $3 \times 3 \times 0.5 \mathrm{~cm}^{3}$ using a cutting machine. (ii) To prepare a suitable concentration of pigment paste, a gelatine (TianLli Chemical Reagent Co., Ltd., Hebei, China) solution with a mass concentration of $4 \%$ was mixed with mineral pigments, based on a 2:1 mass ratio. The mineral pigments included iron oxide red, cinnabar, malachite green, and ultramarine, made at the JinBiZhai art pigment factory (Beijing, China). Each of the four pigments was applied to the surface of the pottery pieces mentioned above with a brush $0.1-0.2 \mathrm{~mm}$ thick, and dried at room temperature. (iii) Six grams of ZB-F600 emulsion (Zhenbang Fluorine PaintCo., Ltd., Dalian, Liaoning, China) were diluted with $100 \mathrm{~mL}$ of water, followed by stirring for $20 \mathrm{~min}$. The diluted emulsion was applied to the pottery piece using a brush and dried at room temperature.

\subsection{Chromatic Aberration Test}

VS-450 (X-Rite, Grand Rapids, Michigan, USA) was used to test the chromatic aberration of the simulated painted pottery before and after the reinforcement treatment. The D65 standard light source and the ISO11 467:2000 standard CIE L $\times a \times b \times$ system were used to record the color change in the simulated painted pottery.

\subsection{Adhesion Test}

The adhesion of the reinforcing agent was tested via the cross-hatch method. The specific method involves using a blade to make six parallel knife marks on the surface of the painted layer (length: 10-20 mm; the distance between the cut marks is $1 \mathrm{~mm}$ ), and a cut is made through the entire paint layer. Then, the same six marks are made similar to the former. The cut marks are vertical to form a small square, and a tape is attached to the entire grid and torn at the smallest angle. The test results can be obtained according to the area ratio of the peeled pigment on the painted surface. According to the national standard GB/T1720-1989 for testing, Level 5 is the best, and Level 0 is the worst (see Figure 3).

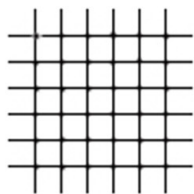

Level 0

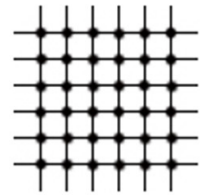

Level 1

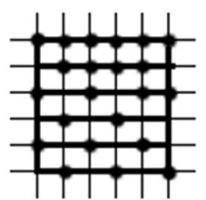

Level 2

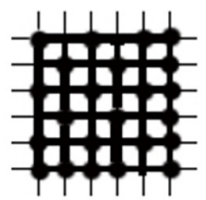

Level 3

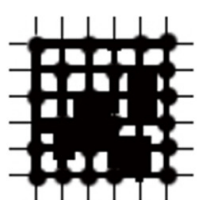

Level 4
Above Level 4 Severely peeled

Level 5

Note: Level 0 is the best; Level 5 is the worst

Figure 3. Standard of the adhesion test.

\subsection{Contact Angle Test}

A contact angle system (OCA 20, Datphysics Instruments GmbH, Filderstadt, Germany) was used under the condition of a fixed water volume of $2 \mu \mathrm{L}$. The contact angle of 
the simulated painted pottery was measured before and after the treatment. The contact angle was the average of three measurements.

\subsection{Scanning Electron Microscope}

A scanning electron microscope (Quant 200, FEI, Hillsboro, OR, USA) was used to observe the surface morphology of the simulated painted pottery before and after treatment. The sample was sputtered with gold, the magnification was 1200, and the acceleration voltage was $20.0 \mathrm{kV}$.

\subsection{Thermal Stability Properties}

To evaluate the effect of ZB-F600 on thermal stability, the thermogravimetric analysis (TG) was performed on pure ZB-F600 at a heated rate of $20^{\circ} \mathrm{C} / \mathrm{min}$ from 25 to $800^{\circ} \mathrm{C}$.

\subsection{Equipment}

A microscopic dynamic monitoring device (self-assembly, see Figure 4) [29] for micronlevel cracks was used to restore the painted layer of cultural ceramic relics. A super image processor was set on the left side and a tripod was set on the right side of the workbench; furthermore, a lens clamp with the lens was set on the upper end of the tripod. The lens was connected with the super image processor through the optical fiber to form a super depth-of-field microscope. A restoration table was arranged on the workbench between the super image processor and the tripod. The tripod had to be rotated to adjust the lens to make the super image processor clearly display the cracks, to fix the cultural relics, and to close the cracks with the reattachment restoration agent. The utility model device could accurately locate the micron-level cracks in the painted layer, accurately measure the size of the cracks, realize multi-angle and omni-directional observations, and collect images and process videos in real time. The collected data and images were intuitive and precise, and the restored cracks were completely closed and fitted.

The device was equipped with a high-performance ultra-depth-of-field microscope (KEYENCK, VXH600, Shanghai, China) that integrates all functions of condensed observation, recording, and measurement. It can achieve a large depth-of-field observation (20-5000 times), as well as clear and accurate observations of large concave and convex samples that cannot be fully focused on with traditional microscopes. Furthermore, it can locate the position of the micron-level cracks in the painted layer; precisely measure the length, width, and tilt angle of the ceramic cultural relics; and realise the two-dimensional positioning of the target observation. Additionally, the image processor of the ultradepth-of-field microscope can produce ultra-strong color and has ultra-high fine resolution capabilities. The transmission speed is fast (more than 20 frames per second) and can be divided into screen observations, on-site storage, and recorded images; it can be used for 2D measurements and fast depth synthesis of 2D and 3D displays. Moreover, a simple two-step operation can create fully focused 2D and 3D images and engage in real-time 2D and 3D image splicing.

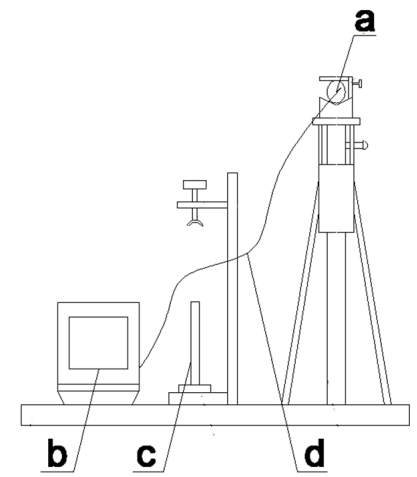

Figure 4. A micron-level crack microscopic dynamic monitoring device; (a) camera lens, (b) image processor, (c) axis of rotation, (d) optical fiber. 


\subsection{Methods}

By adjusting the angle of the depth-of-field microscope, cooperating with the movement of the cultural relics installed on the rotating shaft, a multi-angle observation was achieved through the fine adjustment of the adjusting handle of the tripod, eliminating blind spots on the target. The omni-directional observation was achieved by shifting the observation direction. The accurate position, size, and angle of micron-level cracks in the painted layer were seen through monitoring and auxiliary observations of the data, images, and videos.

\section{Results and Discussion}

\subsection{Chromatic Aberration and Adhesion Changes}

The $\Delta \mathrm{E}^{*}$ values of untreated and treated painted pottery with water-borne fluoropolymer are listed in Table 1. The chromatic aberration of the four treated pieces of painted pottery is less than 1 . In general, a $\Delta \mathrm{E}^{*}$ value of less than 1.5 is undetectable by the human eye [30,31]. Therefore, ZB-F600 water-borne fluoropolymer treatment did not influence the appearance of the painted pottery, which conforms to the principle of 'maintaining the original appearance of cultural relics'. In addition, the adhesion of the four pigmented layers before and after treatment was tested. The results show that the adhesive force of the painted layer was significantly improved after treatment, indicating that ZB-F600 water-borne fluoropolymer can be used as an adhesive agent in the restoration of painted pottery.

Table 1. Chromatic aberration and adhesion changes of untreated and treated portions of the simulated painted pottery.

\begin{tabular}{lccccc}
\hline \multicolumn{1}{c}{ Sample } & $\mathbf{L}^{*}$ & $\mathbf{a}^{*}$ & $\mathbf{b}^{*}$ & $\mathbf{\Delta \mathbf { E } ^ { * }}$ & Adhesion \\
\hline Untreated-iron oxide red & 35.56 & 18.63 & 16.79 & & Level 3 \\
Treated-iron oxide red & 34.44 & 18.58 & 17.01 & 0.67 & Level 1 \\
Untreated-malachite green & 71.85 & -26.67 & 10.68 & & Level 3 \\
Treated-malachite green & 73.55 & -26.17 & 10.48 & 0.71 & Level 1 \\
Untreated-ultramarine & 35.41 & 6.99 & -42.83 & & Level 4 \\
Treated-ultramarine & 35.54 & 6.58 & -42.01 & 0.87 & Level 1 \\
Untreated-cinnabar & 47.95 & 40.83 & 22.53 & & Level 3 \\
Treated-cinnabar & 49.06 & 39.64 & 21.86 & 0.76 & Level 1 \\
\hline
\end{tabular}

\subsection{Hydrophobic Performance}

Figure 5 shows the contact angle of the treated and untreated samples for the four pigmented layers. The untreated surface was completely hydrophilic. Compared with it, the contact angle of the pieces treated with ZB-F600 water-based fluoride was significantly increased. The hydrophilicity of the samples treated with ZB-F600 water-borne fluoropolymer decreased and had a certain degree of hydrophobicity.

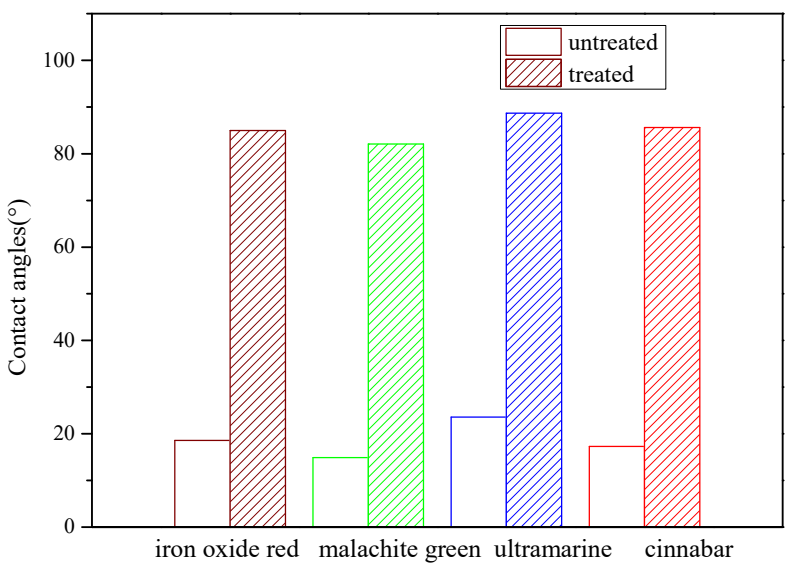

Figure 5. Contact angle of the treated and untreated samples for the four pigmented layers. 


\subsection{Scanning Electron Microscopy (SEM) Analysis}

The surface morphologies were analyzed via SEM to further study the reinforcement effects of ZB-F600 water-borne fluoropolymer. The micro morphology of untreated and treated cinnabar samples at a magnification factor of 600 are shown in Figure 6. The results indicate that the untreated cinnabar pigmented layer surface was formed by the different sizes of pigment particles. Meanwhile, there were a lot of pores in the pigmented layer, suggesting poor connection among the pigment particles. Compared with the untreated samples, the pigment particles of the treated samples had a fuzzy edge, which were cemented as a whole because the ZB-F600 water-borne fluoropolymer was cemented and filled some pores. Therefore, ZB-F600 can change the separated pigmented particle microstructure to form a dense film structure and significantly improve the loose nature of the pigmented particles. This dense film structure provided the consolidated pigment layer good water resistance and stability.
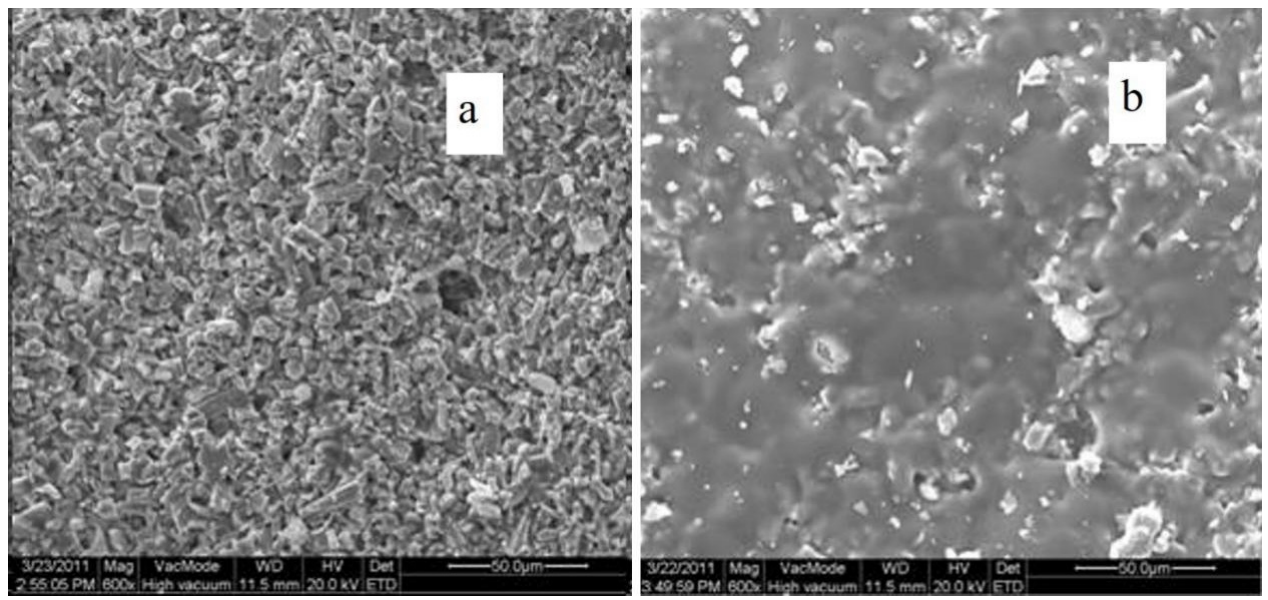

Figure 6. Micro morphology of the untreated (a) and treated (b) cinnabar samples.

\subsection{Thermal Stability}

The TG and derivative thermogravimetry (DTG) curves of pure ZB-F600 under nitrogen are displayed in Figure 7. There was a 5\% loss in temperature (Td5\%) of the ZB-F600 at $272.0^{\circ} \mathrm{C}$. The onset decomposition temperature, Tonset, was $318.3^{\circ} \mathrm{C}$, and the maximum thermal decomposition temperature, Tmax, was $353.69^{\circ} \mathrm{C}$. These results signal that ZB-F600 has excellent thermal stability.

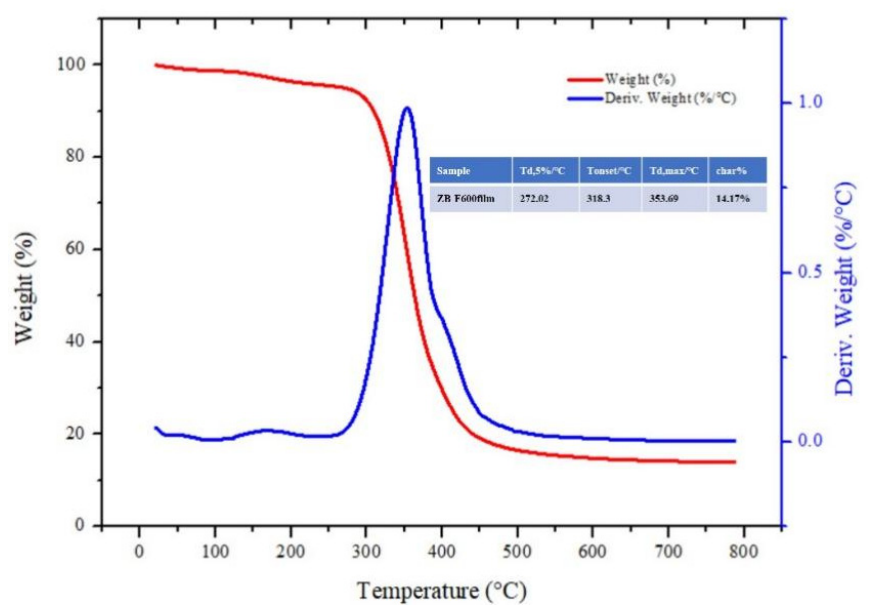

Figure 7. TG and DTG curves of pure ZB-F600 under nitrogen. 
4.5. Monitoring of the Restoration Process: A Case Study of the Painted Terracotta Warriors of the Western Han Dynasty

As presented in Figure 8, for the macroscopic cracks $(>0.1 \mathrm{~mm})$, the restoration agent [32] was directly injected. For the micron-level cracks $(<0.1 \mathrm{~mm})$, our method involved repair using the ultra-depth-of-field microscope. The dynamic detection system for the micron, meter-level cracks included a repair table, an ultra-deep field optical microscope, and an optical system [33]. The multi-channel image data transmission switching system included a host and terminal. During the restoration process, the cultural relics were fixed on the restoration table. The host connected and controlled the displacement system of the restoration table to adjust its position and angle. The multi-channel image data transmission switching system connected the optical system to the ultra depth-of-field optical microscope through data lines and optical fibers. Then, the multi-channel image data transmission and switching system was connected to the host and the terminal through a data line, and various controls and images of the host were displayed on the terminal. The restoration process was controlled by the host computer to select real-time acquisition of images and to process the video.

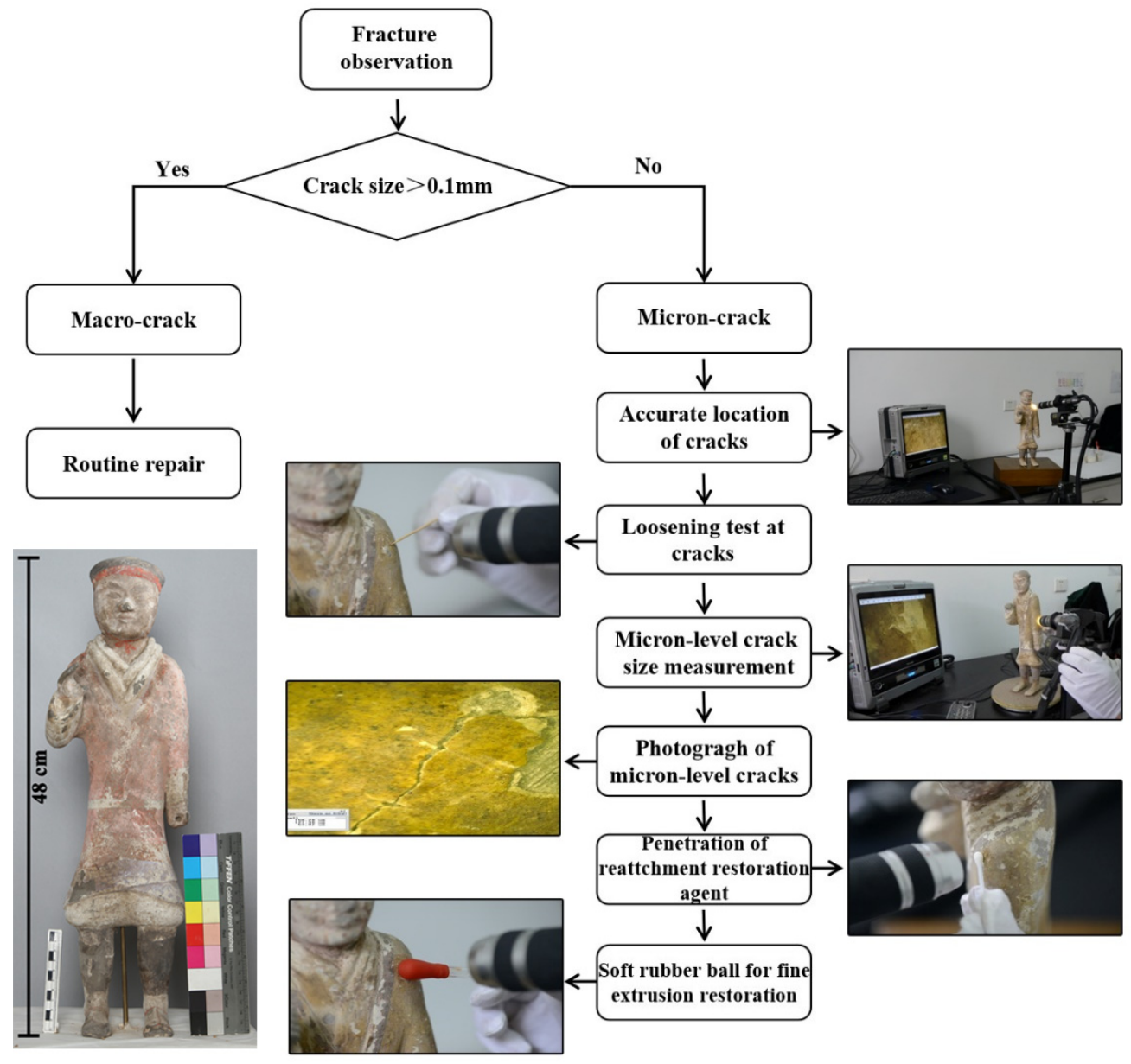

Figure 8. Process of microscopic imaging technology, assisted dynamic monitoring, and restoration.

The specific repair process is outline below (see Figure 9). 

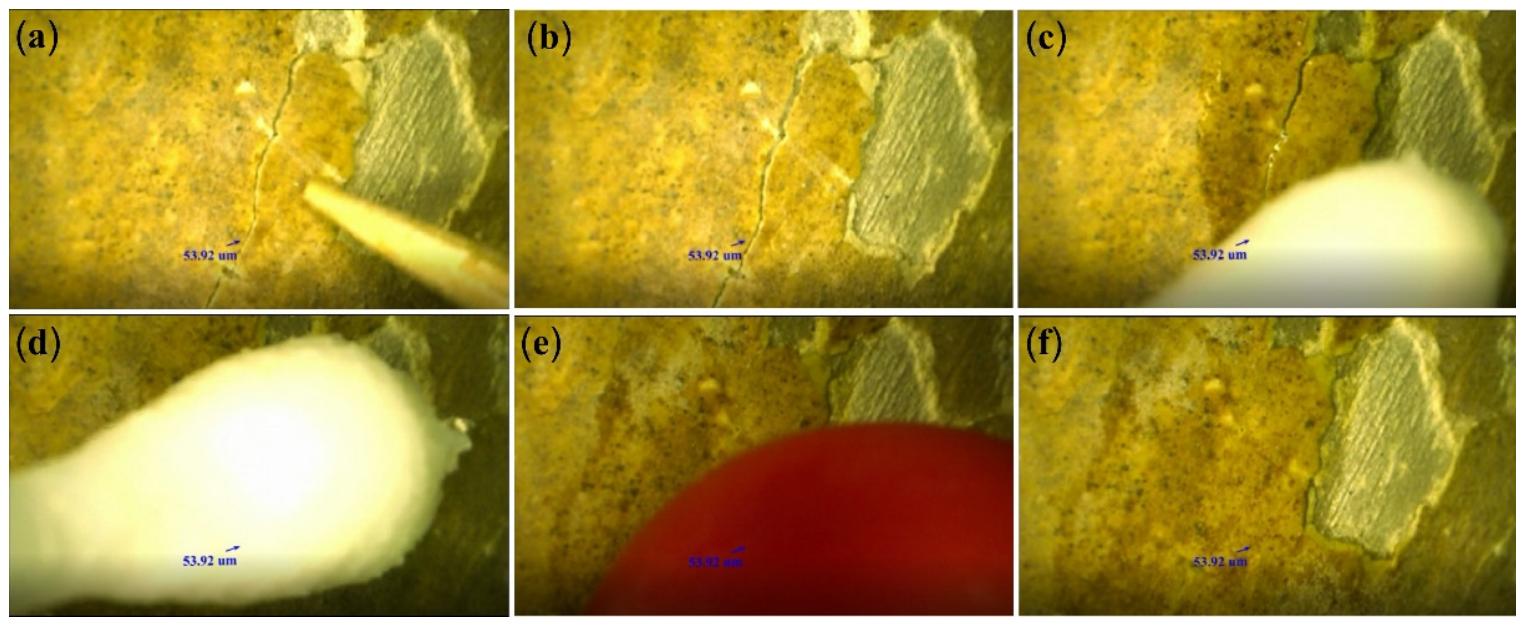

Figure 9. Restoration process of the micron-level cracks. (a) Crack location, (b) crack measurement, (c) penetration of the adhesive agent, (d) air is removed from the cracks, (e) pressing and restoration, (f) after restoration.

\subsubsection{Locating the Cracks}

The ceramic relics were installed on the rotating shaft. The lens of the ultra-depth-offield microscope was adjusted, and the painted layer of the ceramic relics was focused on. The relics were rotated around the axis, and observations were made through the super image processor of the ultra-depth-of-field microscope to locate the micron-level cracks in the painted layer (see Figure 9a). The horizontal or vertical adjusting handle of the tripod was used to rotate the lens of the microscope until the ultra-imaging processor clearly showed the cracks; the adjusting screw was rotated to clamp and fix the ceramic relics with a fixed plate for visual monitoring and auxiliary observation.

\subsubsection{Evaluation and Measurement of the Crack Development}

Through the digital microscopic imaging of the system, the information of the microscopic morphology, size, and geometric spaces of the cracks was obtained intuitively, and was used to judge their development in the painted layer to be restored (see Figure 9b) [34,35].

\subsubsection{Penetration of the Adhesive Agent}

A cotton swab was dipped in the 6\% ZB-F600 water-borne fluoropolymer to bond the micro-level cracks under the microscope display screen (see Figure 9c).

\subsubsection{Pressing the Cracks in the Painted Layer}

The painted layer was gently pressed to the cracks with the cotton swab to remove air from inside the cracks (see Figure 9d). Then, the painted layer was squeezed at the cracks with a soft rubber ball; the cracks were fully closed and fitted together (see Figure 9e). The microsystem photography function was used to take pictures of the repaired cracks (see Figure 9f) and the restoration effect is demonstrated in Figure 10. 


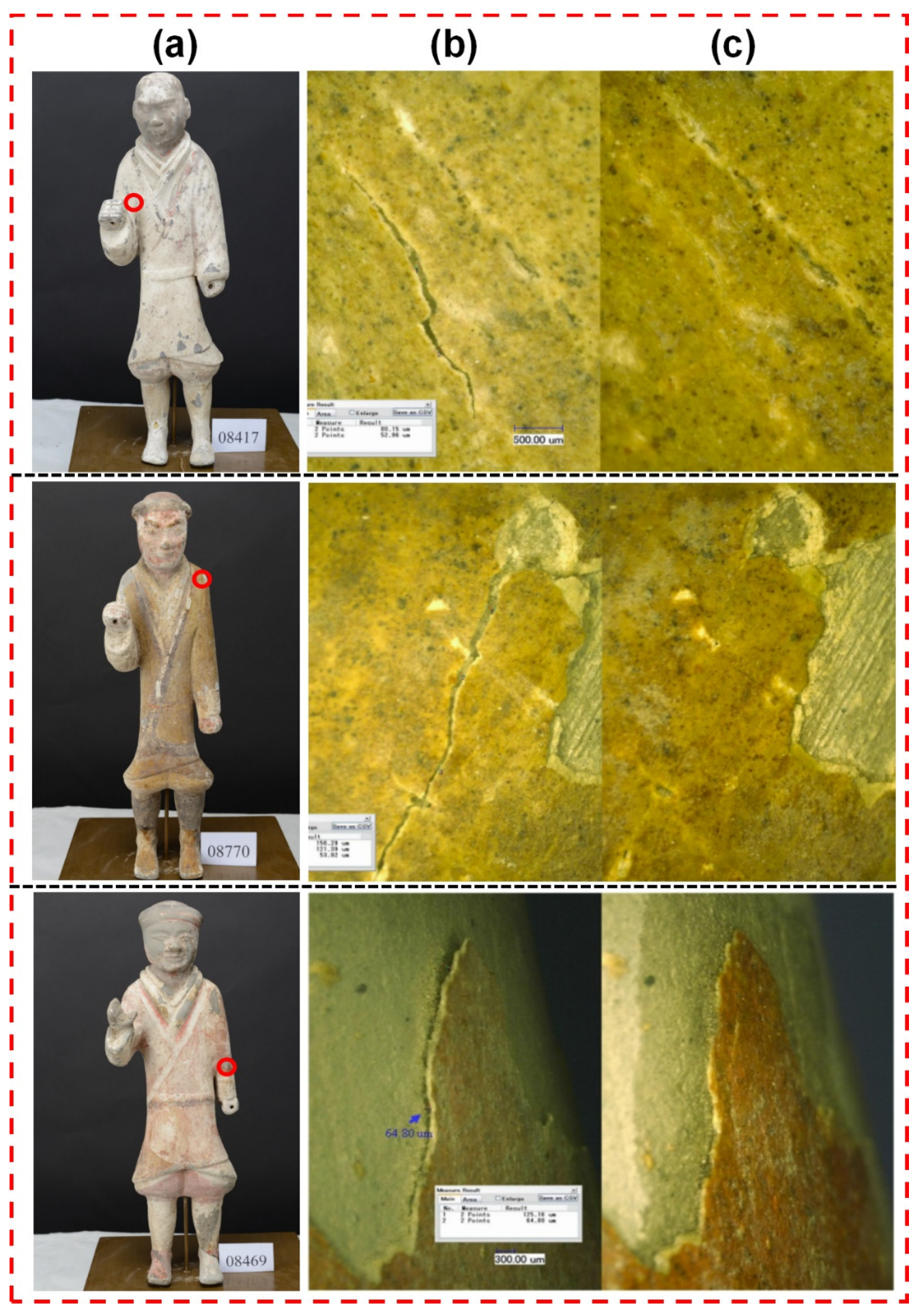

Figure 10. Restoration effect of the painted layer ((a) pottery, (b) untreated, (c) treated).

\section{Conclusions}

This paper examined the painted terracotta warriors and horses from the Western Han Dynasty at the Xianyang Museum, and studied the use of ZB-F600 water-borne fluoropolymer as an adhesive agent to repair micron-level cracks. This was done by employing super depth-of-field digital microscopic imaging technology to build an operating platform for an optical imaging monitoring system. By making simulated painted pottery, the color difference of simulated painted pottery before and after treatment was tested. The $\Delta \mathrm{E}^{*}$ value of samples after treatment was less than 1, indicating that ZB-F600 water-borne 
fluoropolymer did not change the original color. The results of the adhesion test show that ZB-F600 water-borne fluoropolymer treatment can improve the adhesion between the painted layer and the pottery matrix. The test results of the contact angle of the untreated and treated painted layer indicate that the contact angle of the treated painted layer significantly improved, which can help preserve the painted cultural relics. The scanning electron microscope results revealed that ZB-F600 water-borne fluoropolymer encased the loose pigment particles and filled in the pores between the particles, forming a dense film on the surface. This suggests that ZB-F600 water-borne fluoropolymer can be used as an adhesive agent for micron-level cracks. The repair process of micron-level cracks was determined using a super depth-of-field, digital microscopic imaging technology. Microscopic imaging can directly obtain the micro-morphology, size, geometry, and spaces of cracks, information that can be used to judge the development of cracks in the coating layer to be repaired. Furthermore, dynamic monitoring and imaging systems can be used to assist prosthetists with visualizing micro-restoration operations in real time, visual fine surgery during restoration, and recording dynamic video of the entire process. The findings imply that the microscopic image-assisted technique has great potential in the dynamic monitoring and restoration of cultural relics; it also improves the visualization method for the repair of micron-level cracks in painted pottery relics.

Author Contributions: J.W. conceived the research, designed the methodology, performed experiments, gathered and processed data, and drafted the manuscript; B.M. and J.L. gathered data; Y.C. and Y.H. performed data acquisition processing; Y.L. and X.C. discussed the results and reviewed and corrected the manuscript; B.M. and J.C. designed the methodology, conducted data analysis, and revised the manuscript; Y.L., B.M. and J.C. contributed equally to this work. All authors have read and agreed to the published version of the manuscript.

Funding: The authors gratefully acknowledge the financial support provided by the National Natural Science Foundation of China (no. 22102094), the Fundamental Research Funds for the Central Universities (GK 202103061, GK 202103058), and the Key Research and Development Program of Shaanxi Province, China (no. 2021SF-457).

Data Availability Statement: The datasets used and/or results obtained in the current study are available from the corresponding author upon request.

Acknowledgments: The authors also wish to thank Xianyang Museum in Xianyang, Shaanxi Province for kindly supporting this project.

Conflicts of Interest: The authors declare no commercial or associative interest that represents a conflict of interest in connection with this work.

$\begin{array}{ll}\text { Abbreviations } \\ \text { Paranoid B72 } & \text { ethyl methacrylate/methyl acrylate copolymer } \\ \text { ZB-F600 } & \text { ZB-F600 water-borne FEVE } \\ \text { 2D } & \text { two-dimensional } \\ \text { 3D } & \text { three-dimensional } \\ \text { SEM } & \text { scanning electronic microscopy } \\ \text { TG } & \text { thermogravimetric analysis } \\ \text { DTG } & \text { derivative thermogravimetry }\end{array}$

\section{References}

1. Liu, X.H. Rare treasure-colored command pottery from western dynasty. Silk Road 1999, 4, 6-18.

2. Zhang, M.D. An example of Han cavalry in the main battle-The terra cotta warriors of the han dynasty tomb in Yangjiawan, Xianyang. Relics Mus. 1992, 6, 22-25.

3. Hou, Y.B.; Ma, Y.N.; Li, K.; Chen, B.; Shi, N.; Yang, W.Z.; Zhang, S.C.; Qi, Z.A.; Zheng, C.Y.; Sun, Z. Brief report on archaeological excavation of the pit outside $\mathrm{m} 3$ of hanyang ling eastern burial tomb. Archaeol. Cult. Relics 2021, 5, 22-39.

4. Liu, H.; Jiao, N.F. Study on the animal remains in the no. 14 external pit of hanyang ling imperial cemetery. Archaeol. Cult. Relics 2019, 1, 120-128. 
5. Zhang, J.J. Brief account of the sculpture art of the painted terra-cotta warriors of the western han dynasty in xuzhou. Sculpture 2001, 1, 38-39.

6. Cheng, Y.N. A preliminary study on the exhibition of qin history. Relics Mus. 2015, 1, 75-79.

7. Cheng, X.P.; Zhang, J.Y. A review on the diseases and mechanism of pottery painting. Archaeol. Luoyang 2020, 1, 91-95.

8. Wang, W.; Duan, Y.; Wu, F. The Microbial Deterioration and Occurrence Mechanism of Relocated Wall Paintings of the Tiantishan Grottoes. In Proceedings of the 4rd International Conference on Science and Engineering in Arts, Heritage, and Archaeology, London, UK, 4-6 June 2018. [CrossRef]

9. Chelazzi, D.; Chevalier, A.; Pizzorusso, G.; Giorgi, R.; Menu, M.; Baglioni, P. Characterization and degradation of poly(vinyl acetate)-based adhesives for canvas paintings. Polym. Degrad. Stab. 2014, 107, 314-320. [CrossRef]

10. Pintus, V.; Wei, S.; Schreiner, M. Accelerated UV ageing studies of acrylic, alkyd, and polyvinyl acetate paints: Influence of inorganic pigments. Microchem. J. 2016, 124, 949-961. [CrossRef]

11. Wei, S.; Pintus, V.; Schreiner, M. Photochemical degradation study of polyvinyl acetate paints used in artworks by Py-GC/MS J. Anal. Appl. Pyrolysis 2012, 97, 158-163. [CrossRef]

12. Sun, F.; Li, J.; He, Z.; Li, Y.; Wang, R.; Xu, H. Gelatin microsphere-based protection treatment for polychromic relics. Mater. Lett. 2021, 282, 128619. [CrossRef]

13. Ntelia, E.; Karapanagiotis, I. Superhydrophobic Paraloid B72. Prog. Org. Coat. 2020, 139, 105224. [CrossRef]

14. Milanesi, C.; Baldi, F.; Borin, S.; Brusetti, L.; Ciampolini, F.; Iacopini, F.; Cresti, M. Deterioration of medieval painting in the chapel of the Holy Nail, Siena (Italy) partially treated with Paraloid B72. Int. Biodeterior. Biodegrad. 2009, 63, 844-850. [CrossRef]

15. Vaz, M.F.; Pires, J.; Carvalho, A.P. Effect of the impregnation treatment with Par-aloid B-72 on the properties of old Portuguese ceramic tiles. J. Cult. Herit. 2008, 9, 269-276. [CrossRef]

16. Kotlík, P.; Doubravová, K.; Horálek, J.; Kubáč, L.; Akrman, J. Acrylic copolymer coatings for protection against UV rays J. Cult. Herit. 2014, 15, 44-48. [CrossRef]

17. Cultrone, G.; Madkour, F. Evaluation of the effectiveness of treatment products in improving the quality of ceramics used in new and historical buildings. J. Cult. Herit. 2013, 14, 304-310. [CrossRef]

18. Piccinini, F.; Levi, M.; Turri, S. Photoactive sol-gel hybridcoatings from modified fluorocarbon polymers and amorphous titania. Prog. Org. Coat. 2013, 76, 1265-1272. [CrossRef]

19. Lopez, A.B.; Bohórquez, S.J.; Meeuwisse, M.; Mestach, D.; dea Cal, J.C.; Asua, J.M. Self-matting waterborne fluoropolymers Prog. Org. Coat. 2018, 116, 57-69. [CrossRef]

20. Fu, P.; Teri, G.L.; Li, J.; Li, J.X.; Li, Y.H.; Yang, H. Investigation of ancient architectural painting from the Taidong tomb in the western qing tombs, hebei, china. Coatings 2020, 10, 688. [CrossRef]

21. Qi, Y.; Jia, Z.; Zhou, Y.; Wang, Y.; Zhao, G.; Chao, X.; Xing, H.; Li, Y. Application of ethylene oxide gas and argon gas mixture system method for scale deacidif zSZication of cellulose-based cultural heritage collections. Coatings 2021, 11, 973. [CrossRef]

22. Fu, P.; Teri, G.L.; Li, J.X.; Huo, Y.J.; Yang, H.; Li, Y.H. Analysis of an ancient architectural painting from the Jiangxue palace in the imperial museum, Beijing, China. Anal. Lett. 2020, 54, 684-697. [CrossRef]

23. LLiu, Z.-F.; Zhang, H.; Zhou, W.-H.; Hao, S.-C.; Zhou, Z.; Qi, X.-K.; Shi, J.-L. Pigment identification on an undated Chinese painting by non-destructive analysis. Vib. Spectrosc. 2019, 101, 28-33. [CrossRef]

24. Su, B.M.; Jiang, D.Q.; Ma, X.S.; Fan, Z.X.; Zhao, L.Y. Application in synthesized methods of deformation monitoring of the ruins of ancient Jiaohe city. Dunhuang Res. 2007, 5, 39-44.

25. Wang, W.F.; Li, Z.X.; Ma, Z.F.; Fu, Y.X.; Liu, T.; Yang, T.; Fan, Z.; Li, S. The conservation technology of the seriously damaged wall paintings locates at the ancient cultural sites in tibetan. Dunhuang Res. 2005, 4, $24-29$.

26. Lan, D.S.; Rong, B.; Xia, Y.; Zhou, T.; Wang, D.F. Reattachment of paint and restoration of qin polychrome terra-cotta warriors. Sci. Conserv. Archaeol. 2016, 28, 60-66. [CrossRef]

27. Ma, Z.Z.; Wang, L.Q.; Vaclav, P. The influence of the photothermal aging exerting on the gc-ms identification of the common proteinaceous binding media in polychromy artworks. J. Northwest Univ. 2020, 50, 595-605. [CrossRef]

28. Cauzzi, D.; Chiavari, G.; Montalbani, S.; Melucci, D.; Cam, D.; Ling, H. Spectroscopic and chromatographic studies of sculptural polychromy in the zhongshan grottoes (r.P.C.). J. Cult. Herit. 2013, 14, 70-75. [CrossRef]

29. Wang, J.L.; Li, Y.H.; Feng, P.; Tong, G.G.; Jing, C. Micro Dynamic Monitoring Device for Micron-Level Cracks in Painted Layers of Pottery Cultural Relics. China Patent 201520878905.9, 6 April 2016.

30. Li, Q.; Xi, S.; Zhang, X. Deacidification of paper relics by plasma technology. J. Cult. Herit. 2014, 15, 159-164. [CrossRef]

31. Huang, J.; Liang, G.; Lu, G.; Zhang, J. Conservation of acidic papers using a dispersion of oleic acid-modified MgO nanoparticles in a non-polar solvent. J. Cult. Herit. 2018, 34, 61-68. [CrossRef]

32. Li, Y.H.; Xiong, K.; Wang, Y.J.; Dou, J.J.; Wang, J.L. A Strengthening Agent for Crisp Powder Pottery Painted Cultural Relics China Patent 201410190654.5, 17 June 2015.

33. Wang, J.L.; Hu, L.Y.; Feng, P.; Tong, G.G.; Cao, J. Micro Dynamic Monitoring Device and Repair Method for Micron Cracks in Painted Layers of Pottery Cultural Relics. China Patent 201510749340.9, 30 December 2015.

34. Balokhonov, R.R.; Romanova, V.A.; Schmauder, S. Computational analysis of deformation and fracture in a composite material on the mesoscale level. Comput. Mater. Sci. 2006, 37, 110-118. [CrossRef]

35. Panin, V.E.; Goldstein, R.V.; Panin, S.V. Mesomechanics of multiple cracking of brittle coatings in a loaded solid. Int. J. Fract. 2008, 150, 37-53. [CrossRef] 